\title{
Geoff Cloke at 65: a pioneer in organometallic chemistry
}

\author{
Polly L. Arnold, ${ }^{\mathrm{a}}$ Jennifer C. Green, ${ }^{\mathrm{b}}$ Malcolm L. H. Green, ${ }^{\mathrm{b}}$ Alexander F. R. Kilpatrick, ${ }^{\mathrm{b}}$ \\ Richard A. Layfield, ${ }^{\mathrm{c}}$ Jason B. Love, ${ }^{\mathrm{a}}$ Dermot O'Hare ${ }^{\mathrm{b}}$ and John F. C. Turner ${ }^{\mathrm{c}}$
}

\footnotetext{
${ }^{a}$ EaStCHEM School of Chemistry, The University of Edinburgh, Joseph Black Building, David Brewster Road, Edinburgh, EH9 3FJ, UK.

${ }^{b}$ Department of Chemistry, University of Oxford, Inorganic Chemistry Laboratory, South Parks Road, Oxford OX1 3QR, UK.

${ }^{c}$ Department of Chemistry, School of Life Sciences, University of Sussex, Brighton, BN1 9QJ, UK.
}

Professor Geoff Cloke FRS celebrates his $65^{\text {th }}$ birthday in 2018. In a career spanning four decades, his research endeavours have accounted for some of the most innovative synthetic chemistry of the modern era, with his many publications describing truly exceptional compounds and experimental methods that portray a unique chemical imagination. In addition to his scientific accomplishments, Cloke can be particularly proud of his successful mentoring, a level of dedication that propelled many students and post-docs on to become research leaders in their own right. In compiling this collection of some of his research articles, a small cross-section of his friends, colleagues and collaborators, wish to pay tribute to his modesty, compassion and generous personality.

\section{The Oxford Years and Metal-Vapour Synthesis}

A native of Hastings in the south-east of England, Cloke attended Balliol College, Oxford, and was awarded a BA in Chemistry in 1975 . His battles with organometallic chemistry as a research student under the 
guidance of M. L. H. Green led to the award of a DPhil entitled The Reactions of Metal Vapours and Related Species in $1978 .{ }^{1}$ The thesis describes an array of ferocious-looking experimental rigs for the atomization of refractory metals using electron-beam furnaces, the associated glass connections being assembled with due acknowledgement to the technical support within the Inorganic Chemical Laboratory, in particular to the ICL glassblower (and Geoff's fellow cricket fan) Mr. Geoff Wilkinson “for many astounding feats of glassblowing." The intellectual and technical accomplishments of this thesis foreshadow the future career of a chemist now renowned for his ability to synthesize amazing organometallic molecules that have challenged the accepted norms of chemical bonding and reactivity, particularly for the d- and f-block elements.

Metal vapour synthesis (MVS) was already established in Malcolm Green's group at Oxford when Geoff started his DPhil. Initially, a neutral hearth had been used for the gun, but this led to electron damage of products. Geoff's challenge was to build an MVS machine using, at its heart, an electron gun furnace with a positive hearth that could achieve the necessary temperatures of $2500-3500^{\circ} \mathrm{C}$. The new machine had a revolutionary design with a liquid-nitrogen-cooled, evacuated bell jar to provide the reaction surface over an electron beam furnace. ${ }^{1}$ Either vapours or solutions could be admitted as reactants (Fig. 1).

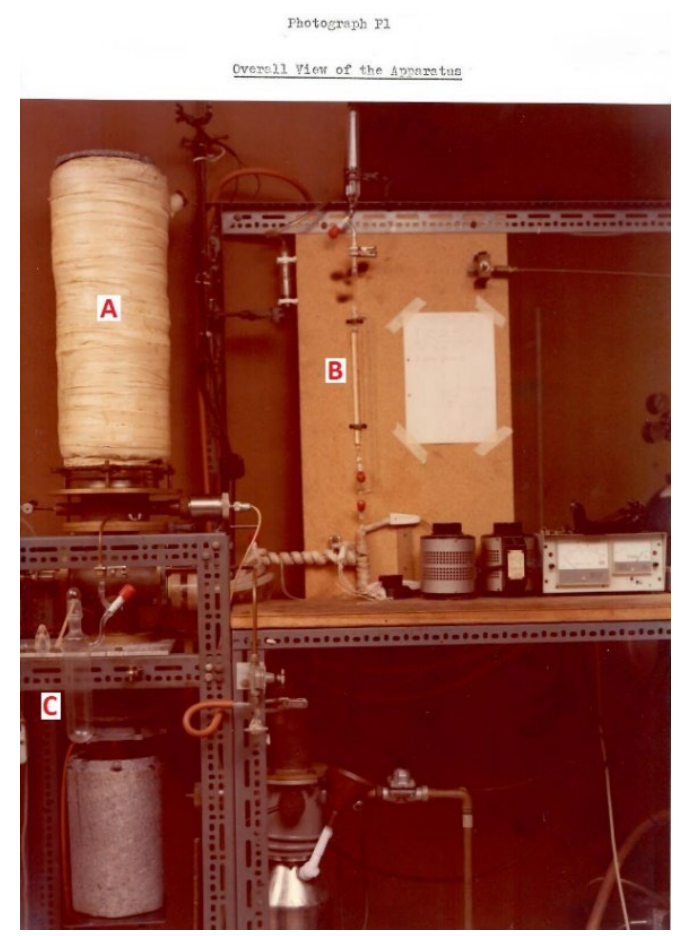

Fig. 1 The metal-vapour synthesis apparatus: (A) reaction vessel; (B) ligand inlet; (C) product vessel. Image taken from reference $1 \mathrm{a} .{ }^{1 \mathrm{a}}$ 
A large-scale synthesis of bis(arene) tungsten compounds was achieved, with tungsten vaporising at a rate of $0.8 \mathrm{~g} \mathrm{~h}^{-1}$. The tungsten sandwich compounds could subsequently be protonated to give the first metal arene hydrides (Scheme 1). ${ }^{2}$

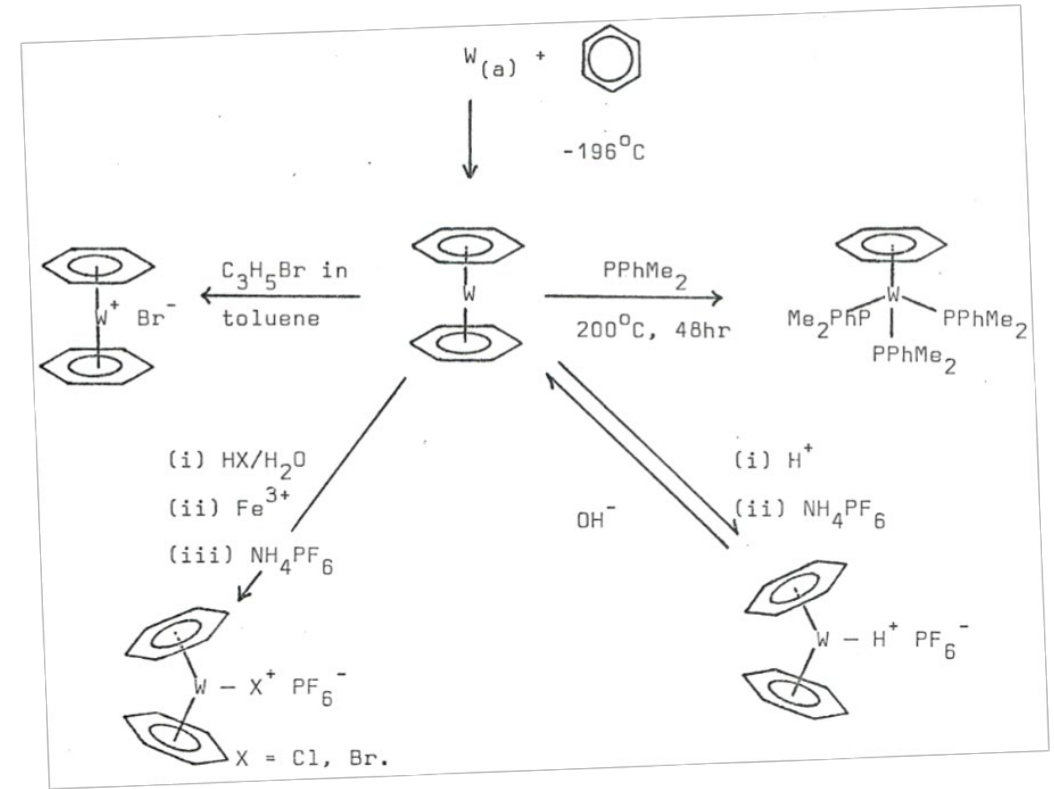

Scheme 1. MVS and reactivity of tungsten bis(benzene) compounds. Image taken from reference 1a.

A flood of novel chemistry ensued, including further metal-arene compounds with zirconium, hafnium, niobium and tantalum. Other volatile ligands employed were cycloheptatriene, ${ }^{3}$ trimethylphosphine, ${ }^{4}$ and $b i s\left(\right.$ dimethylphosphino)ethane. ${ }^{5}$ Use of halocarbons and oxalylchloride gave a range of bi- and tri-nuclear cluster halides or carbonyl halides of molybdenum, rhenium, ruthenium, iridium, and platinum. ${ }^{6}$ Such a wealth of innovative synthesis is a tribute to both Geoff's exceptional experimental skills and genius for design and construction. During his time at Oxford, he also mentored many other research students in the Green group, who benefited from his knowledge and expertise.

\section{Appointment at the University of Sussex}

After completing his DPhil Geoff held an SERC postdoctoral fellowship and subsequently a Junior Research Fellowship at Balliol College. During his tenure of the latter, Geoff spent one year as a postdoc at MIT working with Richard R. Schrock. He returned to Oxford in 1982 before moving to the University of Sussex, 
first holding an SERC Advanced Fellowship in 1983 and subsequently being appointed to a New Blood Lectureship in 1984. With his own research group at Sussex, Geoff broadened his interest to include the rareearth elements and the actinides uranium and thorium. In a spectacular breakthrough, he reported the first formally zerovalent lanthanide compound using the bulky tris-t-butyl benzene as a ligand, namely $\left[\mathrm{Gd}\left({ }^{t} \mathrm{Bu}_{3} \mathrm{C}_{3} \mathrm{H}_{3}\right)_{2}\right]$ and followed by other lanthanide analogues, complete with insightful investigations of the magnetic moments (Fig. 2). ${ }^{7}$

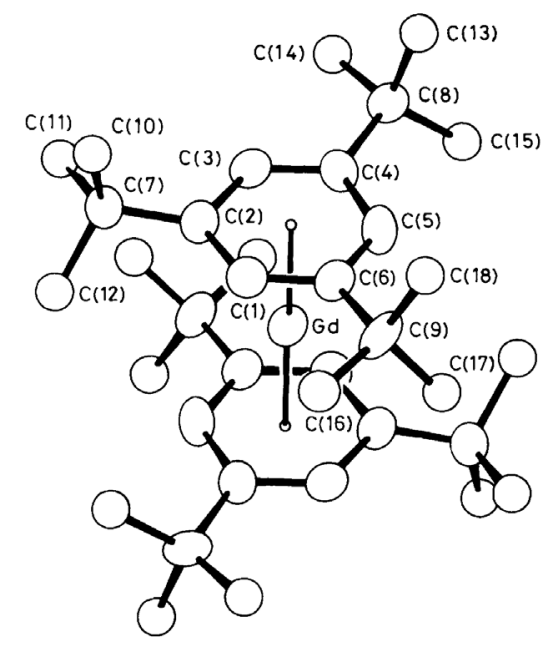

Fig. 2 Molecular structure of $\left[\mathrm{Gd}\left({ }^{t} \mathrm{Bu}_{3} \mathrm{C}_{3} \mathrm{H}_{3}\right)_{2}\right]{ }^{7 \mathrm{a}}$

Geoff was promoted to a personal chair at Sussex in 1994. At that time, the department had an incredibly strong international reputation for organometallic chemistry, including leading lights such as John F. Nixon FRS, Michael F. Lappert FRS, J. David Smith, and Colin Eaborn FRS. The field was still rapidly developing, and Geoff worked on further exemplification of formally zero-valent rare-earth complexes, studying the effect of heteroatom incorporation on stability. ${ }^{8}$ A fruitful collaboration with Nixon looked at the use of metal vapours to catalyse the cyclo-oligomerisation of the volatile, thermally stable tert-butyl phosphaalkyne, ${ }^{t} \mathrm{BuC} \equiv \mathrm{P}$, into new clusters or ligands, yielding a series of phospha-substituted cyclopentadienyl and phosphabenzene complexes from across the periodic table. ${ }^{9,10}$ Since phosphorus incorporation stabilises electron-rich organometallics, the metal atom route yielded new low formal oxidation state complexes of electropositive metals such as scandium(I) and scandium(II). ${ }^{11,12}$ There was also an interesting set of discussions with Harry Kroto (in the year prior to the Nobel prize being awarded for the 
discovery of $\mathrm{C}_{60}$ ) about the use of the MVS technique to explore new methods to make fullerenes. While this was not pursued in depth, the discussions resulted in the MVS machine forming the backdrop to the portrait of Kroto that hangs in the National Portrait Gallery in London.

\section{Metal amide chemistry}

While Geoff has mostly focussed on cyclic $\pi$-systems as ligands for the electropositive metals, he also pioneered the use of simple polydentate amides as ligands, initially with the aim to form highly active alkene polymerisation catalysts of Group 4 metals. The use of trialkylsilyl substituents, well established at Sussex through Geoff's cyclooctatetraene chemistry and Mike Lappert's aziridine chemistry, led to the development of new $\mathrm{C}_{2}$-symmetric naphthyldiamido and diamidoamine ligands and the first Group 4 complexes of these ligands. ${ }^{13}$ The advent of this ligand classification proved prescient, being quickly taken up others worldwide in the hunt for non-metallocene catalysts for alkene polymerisation. Geoff's group proved particularly inventive in naming these ligands, from the initial 'Love' ligand, to its dilithio salt 'Lovelitwo' and 'Whole Lotta Love' for versions with large silyl substituents. While targeting alkene polymerisation catalysis, Geoff also exploited the diamidoamine ligand to look at fundamental organometallic and small-molecule activation chemistry. This led to the discovery of the first non-metallocene titanium(III) hydride (Fig. 3), isolated as a

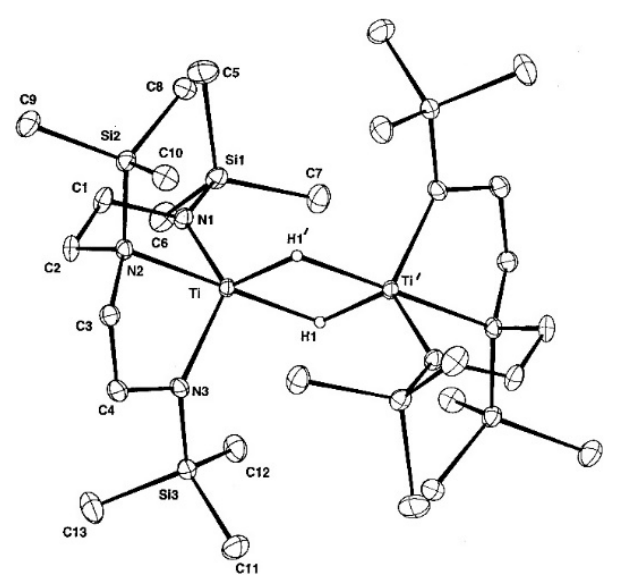

Fig. 3 The first non-metallocene titanium(III) hydride. Reprinted, with permission, from J. B. Love, H. C. S. Clark, F. G. N. Cloke, J. C. Green and P. B. Hitchcock, J. Am. Chem. Soc., 1999, 121, 6843. Copyright 1999 American Chemical Society. ${ }^{14}$ 
dimer by hydrogenolysis of the titanium(III) alkyl, and which was diamagnetic due to a Ti---Ti sigma interaction although the singlet and triplet states were close in energy. ${ }^{14}$

Furthermore, the reduction of vanadium halide complexes of the diamidoamine ligand with $\mathrm{KC}_{8}$ led to the formation of nitride complexes derived from dinitrogen. As with the titanium complexes above, dinuclear complexes were formed and exhibit $\mathrm{V}^{\mathrm{V}}(\mathrm{N})_{2} \mathrm{~V}^{\mathrm{V}}$ cores which can be further reduced to $\mathrm{V}^{\mathrm{V}}(\mathrm{N})_{2} \mathrm{~V}^{\mathrm{IV}}$, in which the $\mathrm{K}$ cation interacts with the nitride core and diamidoamine ligand. ${ }^{15}$ This latter study is significant as the complete scission of the $\mathrm{N} \equiv \mathrm{N}$ triple bond using a metal complex was extremely rare at this time, and initiated a very fruitful foray by Geoff into dinitrogen transformation using low oxidation state uranium compounds.

\section{Pentalene Chemistry}

Cloke is particularly well known for his studies on bulky, substituted pentalene ligands. For many years the pentalene dianion, $\mathrm{C}_{8} \mathrm{H}_{6}{ }^{2-}\left(\mathrm{Pn}^{2-}\right)-$ a fused, bent, dianionic counterpart to cyclopentadienyl - was regarded as an unstable curiosity and not as a ligand worthy of interest from organometallic chemists. Cloke's interest in pentalene came about through an industrially funded alkene polymerisation catalysis project, in which he observed an unanticipated rearrangement of the cyclooctatetraene tantalum complex $\mathrm{Ta}\left(\eta^{8}-\mathrm{C}_{8} \mathrm{H}_{6}\{1,4-\right.$ $\left.\left.\mathrm{SiMe}_{3}\right\}_{2}\right) \mathrm{Cl}_{3}$ on protonolysis, which produced a pentalene derivative, $\mathrm{Ta}\left(\eta^{8}-\mathrm{C}_{8} \mathrm{H}_{4}\left\{1,5-\mathrm{SiMe}_{3}\right\}_{2}\right) \mathrm{Cl}_{3} .{ }^{16} \mathrm{The}$ latter compound represented the first example of a pentalene ligand bound to a single metal centre in an $\eta^{8}$ fashion. Cloke saw an opportunity to use pentalene ligands to sterically and electronically stabilise $f$-and early $d$-block metal centres. This provided Geoff with the perfect excuse for a summer spent in Lab 14, carefully tinkering with a homemade flash vacuum pyrolysis apparatus: by this time, the joke in the Sussex mechanical workshop was that drawers were being fitted with 'anti-Cloking devices' in an attempt to stop the disappearance of tools and fittings. However, the results of this work were the first reliable and high-yielding methods for the synthesis of alkali metal pentalenyl and their bulky 1,4-triisopropylsilyl substituted derivatives, $\left[\mathrm{Pn}^{\dagger}\right]^{2-} \cdot{ }^{17}$ The use of these sterically demanding pentalene ligands in the stabilisation of actinide elements was first exemplified by Geoff and co-workers in 1997 with the synthesis of thorium bis(pentalene), $\operatorname{Th}\left(\eta^{8}-\mathrm{Pn}^{\dagger}\right)_{2}$, which marked a new class of sandwich complex. ${ }^{18}$ In the following year, the 
group reported a syn-bimetallic bis(pentalene) complex, $\mathrm{Mo}_{2}\left(\mu: \eta^{5}, \eta^{5}-\mathrm{Pn}^{\dagger}\right)_{2}$, confirming for the first time by X-ray diffraction the double-sandwich structure. ${ }^{19}$

In the subsequent twenty years, the Cloke group has continued to illustrate the versatility of the pentalene ligand in its organometallic complexes, which display interesting electronic and magnetic properties and also show novel reactivity with small molecules. ${ }^{20}$ Most notably, the reversible reaction of uranium(III) ‘mixed-sandwich’ complex $\left(\eta^{8}-\mathrm{Pn}^{\dagger}\right) \mathrm{UCp}^{*}$ with dinitrogen, in which the di-uranium(IV) product features a side-on bridging $\mathrm{N}_{2}$ ligand in its molecular structure (Fig 4). ${ }^{21}$ Strikingly, in this 2002 communication, the only other author is Sussex's former crystallographer, Peter Hitchcock.

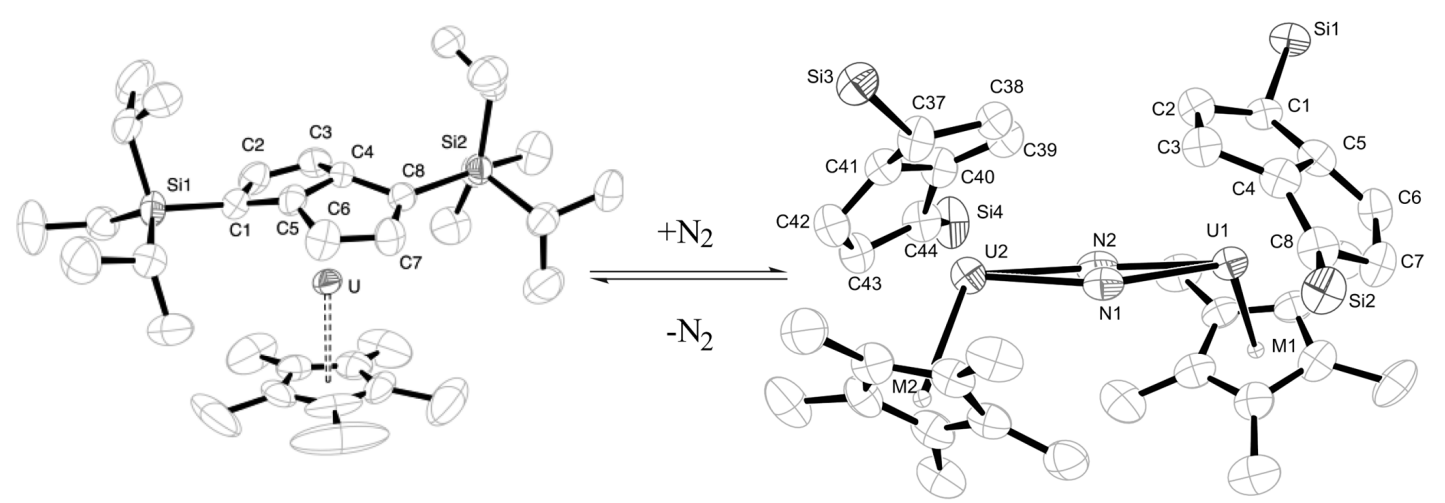

Fig. 4 Reduction of dinitrogen by a uranium(III) pentalene complex. Reprinted, with permission, from F. G. N. Cloke and P. B. Hitchcock, J. Am. Chem. Soc., 2002, 124, 9352. Copyright 2002 American Chemical Society. ${ }^{21}$

More recently, the di-titanium bis(pentalene) complex $\mathrm{Ti}_{2}\left(\mu: \eta^{5}, \eta^{5}-\mathrm{Pn}^{\dagger}\right)_{2}{ }^{22}$ has shown fascinating reactivity with a variety of small molecules including carbon monoxide, carbon dioxide, ${ }^{23}$ and carbon suboxide, ${ }^{24}$ as well as effecting $\mathrm{C}-\mathrm{H}$ and $\mathrm{H}-\mathrm{H}$ bond activations, ${ }^{25}$ and a pentalene-ligated single-molecule magnet was published by Cloke et al. in $2018 .{ }^{26}$ In addition, the Cloke group has made many important discoveries using low-valent cyclooctatetraene uranium complexes, including the seminal discovery that the uranium(III) species $\left[\mathrm{U}\left(\eta-\mathrm{COT}^{\dagger}\right)\left(\eta-\mathrm{Cp}^{*}\right)(\mathrm{THF})\right]$ is capable of cyclotrimerizing carbon monoxide, producing the deltate-ligated complex $\left[\left\{\mathrm{U}\left(\eta-\mathrm{COT}^{\dagger}\right)\left(\eta-\mathrm{Cp}^{*}\right)\right\}_{2}\left(\mathrm{C}_{3} \mathrm{O}_{3}\right)\right] \cdot{ }^{27}$ 


\section{Closing remarks}

Cloke's contributions to chemistry have been recognised through the Corday-Morgan, Tilden and Sir Geoffrey Wilkinson Prizes of the Royal Society of Chemistry, and by the Royal Society upon his election to the Fellowship in 2007. The selection of work cited in this editorial has been compiled as an online collection, which we are sure will provide inspiration for future generations of organometallic chemists. Away from the laboratory, Cloke served a seven-year term as Head of Chemistry in Sussex. Whilst successfully steering the Department through some challenging times, Geoff also led from the front by taking on a full teaching and examining load, delivering lectures that portrayed to Sussex undergraduates an image of an inspired and inspiring teacher. As Head, he galvanized the Chemistry team in a way that created a happy, friendly working environment characterized by excellent collegiality, the legacy of which exists today. We congratulate Geoff - our friend, colleague and mentor - on the occasion of his $65^{\text {th }}$ birthday, and we wish him many more contented days in his woodwork shed and, of course, in Lab 14.

\section{References}

1. (a) F. G. N. Cloke, The Reactions of Metal Vapours and Related Species, DPhil Thesis, University of Oxford, 1978. (b) F. G. N. Cloke and M. L. H. Green, J. Chem. Soc., Chem. Commun., 1979, 127. (c) F. G. N. Cloke, M. L. H. Green and D. H. Price, J. Chem. Soc., Chem. Commun., 1978, 431a.

2. F. G. N. Cloke, M. L. H. Green and G. E. Morris, J. Chem. Soc., Chem. Commun., 1978, 72.

3. F. G. N. Cloke, M. L. H. Green and P. J. Lennon, J. Organomet. Chem., 1980, 188, C25.

4. F. G. N. Cloke, K. P. Cox, M. L. H. Green, J. Bashkin and K. Prout, J. Chem. Soc., Chem. Commun., $1982,393$.

5. F. G. N. Cloke, P. J. Fyne, M. L. H. Green, M. J. Ledoux, A. Gourdon and C. K. Prout, J. Organomet. Chem., 1980, 198, C69.

6. P. R. Brown, F. G. N. Cloke, M. L. H. Green and R. C. Tovey, J. Chem. Soc., Chem. Commun., 1982, 519. 
7. (a) J. G. Brennan, F. G. N. Cloke, A. A. Sameh and A. Zalkin, J. Chem. Soc., Chem. Commun., 1987, 1668. (b) D. M. Anderson, F. G. N. Cloke, P. A. Cox, N. Edelstein, J. C. Green, T. Pang, A. A. Sameh and G. Shalimoff, J. Chem. Soc., Chem. Commun., 1989, 53.

8. P. L. Arnold, F. G. N. Cloke and P. B. Hitchcock, Chem. Commun., 1997, 481.

9. G. K. B. Clentsmith, F. G. N. Cloke, M. D. Francis, J. C. Green, P. B. Hitchcock, J. F. Nixon, J. L. Suter and D. M. Vickers, Dalton Trans., 2000, 1715.

10. A. G. Avent, F. G. N. Cloke, K. R. Flower, P. B. Hitchcock, J. F. Nixon and D. M. Vickers, Angew. Chem. Int. Ed., 1994, 33, 2330.

11. P. L. Arnold, F. G. N. Cloke, P. B. Hitchcock and J. F. Nixon, J. Am. Chem. Soc., 1996, 118, 7630.

12. P. L. Arnold, F. G. N. Cloke and J. F. Nixon, Chem. Commun., 1998, 797.

13. (a) F. G. N. Cloke, P. B. Hitchcock and J. B. Love, J. Chem. Soc., Dalton Trans., 1995, 25. (b) H. C. S. Clark, F. G. N. Cloke, P. B. Hitchcock, J. B. Love and A. P. Wainwright, J. Organomet. Chem., 1995, 501, 333. (c) F. G. N. Cloke, T. J. Geldbach, P. B. Hitchcock and J. B. Love, J. Organomet. Chem., 1996, 506, 343.

14. J. B. Love, H. C. S. Clark, F. G. N. Cloke, J. C. Green and P. B. Hitchcock, J. Am. Chem. Soc., 1999, $121,6843$.

15. G. K. B. Clentsmith, V. M. E. Bates, P. B. Hitchcock and F. G. N. Cloke, J. Am. Chem. Soc., 1999, 121, 10444.

16. Q. A. Abbasali, F. G. N. Cloke, P. B. Hitchcock and S. C. P. Joseph, Chem. Commun., 1997, 1541.

17. F. G. N. Cloke, M. C. Kuchta, R. M. Harker, P. B. Hitchcock and J. S. Parry, Organometallics, 2000, 19, 5795.

18. F. G. N. Cloke and P. B. Hitchcock, J. Am. Chem. Soc., 1997, 119, 7899.

19. M. Kuchta and F. G. N. Cloke, Organometallics, 1998, 17, 1934.

20. (a) O. T. Summerscales and F. G. N. Cloke, Coord. Chem. Rev., 2006, 250, 1122; (b) F. G. N. Cloke, J. C. Green, A. F. R. Kilpatrick and D. O'Hare, Coord. Chem. Rev., 2017, 344, 238. (c) A. F. R. Kilpatrick and F. G. N. Cloke, Dalton Trans., 2017, 46, 5587.

21. F. G. N. Cloke and P. B. Hitchcock, J. Am. Chem. Soc., 2002, 124, 9352.

22. A. F. R. Kilpatrick, J. C. Green, F. G. N. Cloke and N. Tsoureas, Chem. Commun., 2013, 49, 9434.

23. A. F. R. Kilpatrick and F. G. N. Cloke, Chem. Commun., 2014, 50, 2769. 
24. N. Tsoureas, J. Green, F. G. N. Cloke, H. Puschmann, M. Roe and G. J. Tizzard, Chem. Sci., 2018, 9, 5008.

25. N. Tsoureas, J. C. Green and F. G. N. Cloke, Chem. Commun., 2017, 53, 13117.

26. A. F. R. Kilpatrick, F.-S. Guo, B. M. Day, A. Mansikkamäki, R. A. Layfield and F. G. N. Cloke, Chem. Commun., 2018, 54, 7085.

27. (a) O. T. Summerscales, F. G. N. Cloke, P. B. Hitchcock, J. C. Green and N. Hazari, Science, 2006, 311, 829. (b) O. T. Summerscales and F. G. N. Cloke, Struct. Bond (Berlin), 2008, 311, 87. 